AGRARIS: Journal of Agribusiness and Rural Development Research

Vol. 3 No.1 Januari 2017
ENI ISTIYANTI', DIAH RINA KAMARDIANI ${ }^{1}$

${ }^{1}$ Program Studi Agribisnis, Fakultas Pertanian,

Universitas Muhammadiyah Yogyakarta

eniistiyanti@yahoo.com

\title{
Performa Supply Chain Emping Melinjo di Kabupaten Bantul Daerah Istimewa Yogyakarta
}

\author{
DOI: 10.18196/agr.3141
}

\begin{abstract}
Emping melinjo was one of the agroindustry-products that had great potential to be developed. The industry of emping melinjo contributed more on economic growth in the reason of creating jobs and alleviate poverty. The purpose of this study was to describe the performance of supply chain of emping melinjo from upstream to downstream and analyze the efficiency of supply chain of emping melinjo in Bantul regency. Field study to obtain primary data was done through interviews with the practitioners of emping melinjo supply chain (including farmers and merchants of melinjo as well as producers and retailers of melinjo chips). The results of field studies then tabulated and analyzed descriptively and quantitatively using Linear Programming. The analysis showed that there were 37 supply
\end{abstract}

chain networks of emping melinjo in Bantul. The practitioners of upstream supply chain were melinjo farmers, middlemen, traders, wholesalers, and retailers, while in the downstream, were emping melinjo producers, traders, small traders, wholesalers, retailers and consumers. The activities of the doer of emping melinjo supply chain includes purchasing, sales, harvesting, packaging, packing, stripping, storage, loading and unloading, transporting, sorting and grading. The flow of products and money in the supply chain of emping melinjo run smoothly, while the flow of information was sluggish. Based on linear programming analysis the cost of supply chain of emping melinjo would reach minimum level at Rp33,969,264 per week if the production of emping melinjo as many as 25,361 $\mathrm{kg}$ per week which was distributed using 22 networks.

Keywords: activity, efficiency, emping melinjo, supply chain

\section{INTISARI}

Emping melinjo termasuk salah satu produk agroindustri yang memiliki potensi besar untuk dikembangkan. Industri emping melinjo banyak memberikan kontribusi bagi pertumbuhan ekonomi karena dapat menciptakan lapangan kerja dan mengentaskan kemiskinan. Tujuan dari penelitian yaitu mendiskripsikan performa Supply Chain emping melinjo dari hulu sampai hilir dan menganalisis efisiensi supply chain emping melinjo di Kabupaten Bantul. Studi lapangan untuk mendapatkan data primer dilakukan melalui interview terhadap pelaku supply chain (petani dan pedagang melinjo serta pengrajin dan pedagang emping). Hasil studi lapangan kemudian ditabulasi dan dianalisis secara deskriptif dan kuantitatif menggunakan Linear Programming. Hasil analisis menunjukkan terdapat 37 jaringan supply chain emping melinjo di Kabupaten Bantul. Pelaku supply chain bagian hulu meliputi petani melinjo, tengkulak melinjo, pedagang pengumpul, pedagang besar dan pengecer melinjo, sedangkan pelaku di bagian hilir yaitu pengrajin emping melinjo, pedagang pengumpul, pedagang kecil, pedagang besar, pedagang pengecer dan konsumen. Aktivitas pelaku supply chain meliputi pemanenan, pengemasan, pengepakan, penjualan, pembelian, 
pengupasan, penyimpanan, bongkar muat, pengangkutan, sortasi, dan grading. Aliran produk dan aliran uang pada supply chain emping melinjo berjalan lancar, sedangkan aliran informasi pada umumnya kurang lancar. Berdasarkan analisis linear programming menunjukkan bahwa biaya supply chain emping melinjo akan minimum yaitu sebesar Rp33.969.264,00 jika produksi emping melinjo di Bantul sebanyak $25.361 \mathrm{~kg} /$ minggu didistribusikan menggunakan 22 jaringan.

Kata kunci: aktivitas, efisiensi, emping melinjo, supply chain.

\section{PENDAHULUAN}

Emping melinjo merupakan produk agroindustri yang memiliki potensi besar untuk dikembangkan. Industri emping melinjo banyak memberikan kontribusi bagi pertumbuhan ekonomi karena dapat menciptakan lapangan kerja dan mengentaskan kemiskinan. Kabupaten Bantul merupakan sentra industri emping melinjo di Yogyakarta. Industri emping melinjo di Bantul berjumlah 688 unit usaha yang tersebar di semua kecamatan. Sentra industri emping melinjo berada di Kecamatan Banguntapan, Bantul, Pajangan, Piyungan, Jetis dan Pandak. Industri emping melinjo pada umumnya merupakan industri rumah tangga dan lebih sering disebut sebagai industri pedesaan (Badan Pusat Statistik, 2013).

Supply Chain adalah jaringan perusahaan-perusahaan yang secara bersama-sama bekerja untuk menciptakan dan menghantarkan suatu produk ke tangan pemakai akhir. Perusahaan-perusahaan tersebut terdiri dari supplier, pabrik, distributor, toko atau ritel, serta perusahaan-perusahaan seperti perusahaan jasa logistik (Pujawan, 2005). Sedangkan menurut Indrajit dan Richardus (2002) Supply Chain didefinisikan sebagai suatu sistem tempat organisasi menyalurkan barang produksi dan jasanya kepada para pelanggannya.

Supply Chain Management merupakan serangkaian pendekatan yang diterapkan untuk mengintegrasikan pemasok, pengusaha, gudang dan tempat penyimpanan lainnya secara efisien sehingga produk dihasilkan dapat didistribusikan dengan kuantitas yang tepat, lokasi dan waktu yang tepat untuk memperkecil biaya dan memuaskan keinginan pelanggan (Chopra dan Meindl, 2001). Menurut Kotler (2003) Supply chain management mencakup semua interaksi diantara pemasok, produsen, distributor, dan pelanggan. Tujuan utama dari setiap rantai supply adalah memenuhi kebutuhan pelanggan serta memperoleh keuntungan untuk dirinya sendiri. Agar tujuan tercapai maka harus ada akses yang mudah untuk koordinasi, kolaborasi dan integrasi antar pemasok (Moharana, 2012)

Koordinasi pada supply chain dapat ditingkatkan apabila pelaku supply chain mengambil tindakan secara bersama-sama untuk meningkatkan laba total supply chain bukan laba individu. Kurangnya koordinasi terjadi karena setiap pelaku supply chain memapunyai tujuan yang berbeda atau karena adanya distorsi informasi (Sarmah, et. al., 2005). Pelaku supply chain emping melinjo baik di bagian hulu maupun hilir bersifat independen antara satu dengan yang lain. Setiap pelaku supply chain bertindak berdasarkan informasi yang diperolehnya sendiri sehingga sering terjadi distorsi informasi (Mc.Cullen dan Towill, 2002). Pengrajin mendapatkan bahan baku berupa biji melinjo dari pedagang yang menjadi palanggannya demikian juga dalam memasarkan emping melinjo hanya pada pedagang tertentu. Ada pasar yang kekurangan pasokan emping melinjo sebaliknya beberapa pasar kebanyakan pasokan. Akibat keadaan tersebut, keuntungan yang diperoleh pelaku supply chain emping melinjo sangat bervariasi. Tujuan penelitian yaitu mendeskripsikan performa supply chain emping melinjo dilihat dari jaringan, pelaku dan aktivitasnya serta menganalisis efisiensi supply chain emping melinjo di Kabupaten Bantul.

\section{METODE PENELITIAN}

Penelitian dilakukan di Kabupaten Bantul menggunakan metode deskriptif analisis. Teknik pelaksanaan penelitian menggunakan metode survey. Penentuan lokasi penelitian dengan metode purposive sampling berdasarkan pertimbangan Kabupaten Bantul merupakan sentra emping melinjo di Propinsi Daerah Istimewa Yogyakarta. Pengambilan responden pengrajin emping melinjo secara sensus sedangkan penentuan pedagang secara snow boll.

Studi lapangan untuk mendapatkan data primer dilakukan melalui interview dengan petani melinjo di Gunungkidul, Bantul dan Kebumen sebanyak 70 orang, pedagang melinjo (tengkulak, pedagang pengumpul, pedagang besar dan pengecer sebanyak 23 orang, pengrajin emping melinjo di sentra produksi yaitu Kecamatan Banguntapan dan Pajangan berjumlah 91 orang, pedagang emping melinjo meliputi pedagang pengumpul, pedagang kecil, pedagang besar, dan pengecer berjumlah 56 orang. Teknik analisis yang digunakan adalah analisis deskripsi yaitu mendiskripsikan jaringan supply chain, pelaku supply chain emping melinjo dan aktivitasnya, aliran barang, uang dan informasi. Analisis kuantitatif menggunakan program linier (linear programming) untuk mengetahui jaringan supply chain yang efisien dengan model sebagai berikut: 
TABEL I. AKTIVITAS PELAKU SUPPLY CHAIN EMPING MELINJO DI BAGIAN HULU

\begin{tabular}{|c|c|c|c|c|c|c|c|c|c|c|}
\hline \multirow{3}{*}{$\begin{array}{c}\text { Pelaku Supply } \\
\text { Chain }\end{array}$} & \multicolumn{10}{|c|}{ Aktivitas Pelaku (\%) } \\
\hline & \multicolumn{3}{|c|}{ Pertukaran } & \multicolumn{4}{|c|}{ Fisik } & \multicolumn{3}{|c|}{ Fasilitas } \\
\hline & $\begin{array}{l}\text { Pembe } \\
\text { lian } \\
\end{array}$ & $\begin{array}{l}\text { Penjua } \\
\text { lan } \\
\end{array}$ & $\begin{array}{l}\text { Pengupa } \\
\text { san } \\
\end{array}$ & $\begin{array}{l}\text { Pengema } \\
\text { san } \\
\end{array}$ & $\begin{array}{l}\text { Pengepa } \\
\text { kan } \\
\end{array}$ & $\begin{array}{l}\text { Penyimpa } \\
\text { nan } \\
\end{array}$ & $\begin{array}{l}\begin{array}{l}\text { Pengang } \\
\text { kutan }\end{array} \\
\end{array}$ & B.muat & Sortasi & Grading \\
\hline Petani & $X$ & $\sqrt{ }$ & $x$ & 83,3 & $x$ & $x$ & 3,3 & $x$ & $X$ & $X$ \\
\hline Tengkulak & $\sqrt{ }$ & $\sqrt{ }$ & $x$ & $\sqrt{ }$ & $\sqrt{ }$ & $\sqrt{ }$ & $\sqrt{ }$ & $x$ & $X$ & $x$ \\
\hline P.Pengumpul & $\sqrt{ }$ & $\sqrt{ }$ & $x$ & $\sqrt{ }$ & $\sqrt{ }$ & $x$ & $\sqrt{ }$ & 33,3 & $x$ & $x$ \\
\hline P. Besar & $\sqrt{ }$ & $\sqrt{ }$ & $\sqrt{ }$ & $\sqrt{ }$ & $\sqrt{ }$ & $\sqrt{ }$ & 50 & 50 & $\sqrt{ }$ & $\sqrt{ }$ \\
\hline P. Besar LD & $\sqrt{ }$ & $\sqrt{ }$ & $\sqrt{ }$ & $\sqrt{ }$ & $x$ & $\sqrt{ }$ & $\sqrt{ }$ & $\sqrt{ }$ & $x$ & $\sqrt{ }$ \\
\hline P.Pengecer & $\sqrt{ }$ & $\sqrt{ }$ & $X$ & $\sqrt{ }$ & $X$ & $X$ & $X$ & $\sqrt{ }$ & $x$ & $X$ \\
\hline
\end{tabular}

Keterangan:

LD: luar Daerah

$\mathrm{X}$ : Semua pelaku tidak melakukan aktivitas

$\sqrt{ }$ : Semua pelaku melakukan aktivitas

Fungsi Tujuan:

$(\mathrm{Z})=\mathrm{C} 1 \mathrm{~J} 1+\mathrm{C} 2 \mathrm{~J} 2+\mathrm{C} 3 \mathrm{~J} 3+\mathrm{C} 4 \mathrm{~J} 4+\mathrm{C} 5 \mathrm{~J} 5+\mathrm{C} 6 \mathrm{~J} 6+\mathrm{C} 7 \mathrm{~J} 7+$

$\mathrm{C} 8 \mathrm{~J} 8+\mathrm{C} 9 \mathrm{~J} 9+\mathrm{C} 10 \mathrm{~J} 10+\mathrm{C} 11 \mathrm{~J} 11+\mathrm{C} 12 \mathrm{~J} 12+\mathrm{C} 13 \mathrm{~J} 13+$

$\mathrm{C} 14 \mathrm{~J} 14+\mathrm{C} 15 \mathrm{~J} 15+\mathrm{C} 16 \mathrm{~J} 16+\mathrm{C} 17 \mathrm{~J} 17+\mathrm{C} 18 \mathrm{~J} 18+\mathrm{C} 19 \mathrm{~J} 19$

$+\mathrm{C} 20 \mathrm{~J} 20+\mathrm{C} 21 \mathrm{~J} 21+\mathrm{C} 22 \mathrm{~J} 22+\mathrm{C} 23 \mathrm{~J} 23+\mathrm{C} 24 \mathrm{~J} 24+$

$\mathrm{C} 25 \mathrm{~J} 25+\mathrm{C} 26 \mathrm{~J} 26+\mathrm{C} 27 \mathrm{~J} 27+\mathrm{C} 28 \mathrm{~J} 28+\mathrm{C} 29 \mathrm{~J} 29+\mathrm{C} 30 \mathrm{~J} 30$

$+\mathrm{C} 31 \mathrm{~J} 31+\mathrm{C} 32 \mathrm{~J} 32+\mathrm{C} 33 \mathrm{~J} 33+\mathrm{C} 34 \mathrm{~J} 34+\mathrm{C} 35 \mathrm{~J} 35+$

$\mathrm{C} 36 \mathrm{~J} 36+\mathrm{C} 37 \mathrm{~J} 37$

Keterangan $\quad: \mathrm{Z}=$ Total Biaya

$\mathrm{Ci}=$ Biaya Emping Melinjo untuk jaringan ke-i $(\mathrm{Rp} / \mathrm{Kg})$ : Ji = Jaringan Ke-i

Fungsi kendala terdiri dari jumlah pasokan emping melinjo dari pengrajin di Kabupaten Bantul dan permintaan konsumen emping melinjo pada tingkat pedagang pengecer di DIY dan Jawa Tengah yaitu di Pasar Magelang, Pasar Borobudur, Pasar Muntilan, Pasar Klaten, Pasar Beringharjo, Pasar Godean, Pasar Bantul, Pasar Gamping, Pasar Temanggung, Pengecer A, dan Pengecer B di Palbapang, Pasar Kotagede, Pasar Ngablak, Pasar Prambanan, Pasar Piyungan, Pasar Sentul, Pasar Ngipek, Pasar Demangan, Pasar Imogiri dan Pasar Parakan.

\section{HASIL DAN PEMBAHASAN}

\section{AKTIVITAS PELAKU SUPPLY CHAIN EMPING MELINJO}

Pelaku supply chain emping melinjo di Kabupaten Bantul terdiri dari pelaku di bagian hulu dan hilir. Pelaku di bagian hulu terdiri dari petani melinjo, tengkulak, pedagang pengumpul, pedagang besar dan pengecer melinjo, sedangkan pelaku di bagian hilir terdiri dari pengrajin emping melinjo, pedagang pengumpul, pedagang kecil, pedagang besar dan pengecer emping melinjo. Keadaan yang sama terjadi pada industri $\mathrm{CPO}$, elemen supply chain terdiri dari suplier bahan baku, produsen $\mathrm{CPO}$, konsumen dalam negeri, konsumen luar negeri dan hutan Indonesia (Widodo, et. al, 2010)

Pelaku di bagian hulu maupun hilir melakukan aktivitas pertukaran, fisik, dan fasilitas (Tabel 1 dan 2). Aktivitas pertukaran berupa pembelian dan penjualan melinjo, semua pelaku melakukan aktivitas tersebut, namun untuk petani tidak melakukan aktivitas pembelian karena petani yang menghasilkan melinjo itu sendiri. Aktivitas fisik berupa kegiatan pengupasan, pengemasan, pengepakan, penyimpanan, pengangkutan, dan bongkar muat. Sedangkan aktivitas fasilitas meliputi kegiatan sortasi dan grading.

\section{Petani Melinjo}

Petani menanam melinjo di lahan pekarangan dan tegalan, dan rata-rata umur melinjo yang ditanam sudah berusia sekitar 20 tahun. Dalam kegiatan budidaya melinjo, petani mengeluarkan biaya tambahan untuk membeli pupuk organik dan pupuk kimia dengan rata-rata biaya Rp21.934 per pohon dan per tahunnya. Tanaman melinjo dapat dipanen 2-3 kali dalam setahun, untuk melakukan kegiatan pemanenan petani memetik langsung dengan cara memanjat pohon melinjo dan dibantu dengan peralatan yang ada. Selain itu petani juga dapat memperkerjakan buruh panen yang diberi upah sebesar Rp50.000 untuk setiap harinya. Petani melinjo tidak melakukan aktivitas fasilitas, hal ini dikarenakan mereka langsung menjual melinjo kepada pedagang. Aktivitas pertukaran yang dilakukan oleh petani melinjo yaitu menjual melinjonya kepada pedagang pengumpul sebanyak $83,33 \%$ dan tengkulak $16,67 \%$. Aktivitas fisik yang dilakukan oleh petani yaitu pengemasan 
dan pengangkutan. Pengemasan dilakukan oleh 83,3\% petani menggunakan karung untuk mengemas, sedangkan 16,67\% petani tidak melakukan kegiatan pengemasan karena hasil panenya langsung dibeli oleh tengkulak. Kegiatan pengangkutan hanya dilakukan oleh satu petani yang menjualnya langsung ke pasar.

\section{Tengkulak Melinjo}

Aktivitas pertukaran yang dilakukan yaitu melakukan pembelian dan penjualan melinjo. Pembelian melinjo berasal dari petani dengan sistem tebasan yaitu harga yang dibayarkan ke petani bergantung pada perkiraan jumlah buah melinjo di pohon. Penjualan yang dilakukan tengkulak yaitu menjual melinjo kepada pedagang pengumpul. Aktivitas fisik yang dilakukan oleh tengkulak yaitu pengemasan, pengepakan, penyimpanan, dan pengangkutan. Pengemasan yang digunakan adalah karung plastik yang dapat menampung melinjo hingga $70 \mathrm{~kg}$, dan biaya pengemasan sebesar Rp2.000. Aktivitas pengangkutan merupakan kegiatan tengkulak untuk menjual melinjo ke pasar dengan kendaraan umum dengan biaya sekitar Rp7.000. Penyimpanan melinjo juga dilakukan oleh tengkulak yaitu hanya menyimpan dalam karung plastik untuk beberapa hari.

\section{Pedagang Pengumpul Melinjo}

Aktivitas pertukaran yang dilakukan pedagang pengumpul yaitu pembelian melinjo dari petani atau dari para tengkulak yang datang langsung di pasar, dan di pasar ini pedagang pengumpul dapat bertemu dengan pedagang besar, pedagang pengecer, dan pengrajin emping melinjo. Aktivitas fisik yang dilakukan oleh pedagang pengumpul yaitu pengemasan, pengepakan, pengangkutan, dan bongkar muat. Pengemasan menggunakan karung plastik yang dapat menampung melinjo hingga 40 kilogram, dan biaya pengemasan sebesar Rp1.000. Sebanyak 33,33\% pedagang pengumpul melakukan kegiatan bongkar muat, yaitu menurunkan melinjo dari truk dengan memperkerjakan jasa bongkar muat.

\section{Pedagang Besar Melinjo Luar Daerah}

Pedagang besar luar daerah merupakan pedagang besar yang berada di Kabupaten Kebumen dan Gunungkidul. Aktivitas pertukaran yang dilakukan oleh pedagang besar adalah pembelian melinjo yang berasal dari pedagang pengumpul kemudian dijual kepada pengecer atau pengrajin emping melinjo. Aktivitas fisik yang dilakukan oleh pedagang besar meliputi pengupasan, pengemasan, pengepakan, penyimpanan, pengangkutan, dan bongkar muat. Pedagang besar bekerjasama dengan ibu-ibu rumah tangga untuk melakukan pengupasan, sortasi dan grading dengan upah sebesar Rp500 per kg. Pengemasan menggunakan karung plastik yang dapat menampung melinjo hingga $70 \mathrm{~kg}$, dengan kisaran biaya pengemasan sebesar Rp2.000- Rp3.000. Penyimpanan dilakukan pada area gudang dengan cara diletakkan diatas lantai, setelah klatak itu kering kemudian dimasukkan ke keranjang bambu yang dapat menampung sampai $25 \mathrm{~kg}$. Pedagang besar yang melakukan pengangkutan dan bongkar muat dengan sebanyak 50\%. Alat yang dipakai untuk pengangkutan yaitu mobil pribadi yang milik pedagang besar. Aktivitas fasilitas yang dilakukan pedagang besar meliputi sortasi dan grading.

\section{Pedagang Besar Melinjo}

Aktivitas pertukaran yang dilakukan oleh pedagang besar adalah membeli langsung klatak dari pedagang besar luar daerah yang berada di Kabupaten Kebumen serta Gunungkidul dan dibawa ke Bantul untuk dijual kembali ke pedagang pengecer. Aktivitas fisik yang dilakukan oleh pedagang besar meliputi pengupasan, pengemasan, penyimpanan, pengangkutan, dan bongkar muat. Pengupasan dilakukan dengan melepas kulit melinjo dari bijinya (klatak), menggunakan pisau dan dikuliti dengan arah melingkar. Pengemasan yang digunakan adalah karung plastik yang dapat menampung melinjo hingga $70 \mathrm{~kg}$. Penyimpanan dilakukan pada area gudang dengan cara dimasukkan ke keranjang bambu yang bisa menampung sampai $25 \mathrm{~kg}$. Aktivitas fasilitas yang dilakukan pedagang besar yaitu grading.

\section{Pedagang Pengecer Melinjo}

Aktivitas pertukaran yang dilakukan oleh pedagang pengecer yaitu membeli klatak dari pedagang besar dan dijual kembali ke pengrajin di Kabupaten Bantul. Aktivitas fisik yang dilakukan oleh pedagang ini yaitu pengemasan, dan bongkar muat. Pengemasan menggunakan karung plastik, dengan biaya pengemasan sebesar Rp2.000.

\section{Pengrajin emping melinjo}

Pengrajin emping melinjo melakukan aktivitas pertukaran yaitu membeli melinjo dari pedagang di pasar kemudian menjual emping melinjo ke pedagang pengumpul, pedagang kecil, pedagang besar dan pedagang pengecer. Aktivitas fisik yang dilakukan oleh pengrajin meliputi pengemasan, pengepakan, penyimpanan, pengangkutan, dan bongkar muat. Pengemasan yang dilakukan pengrajin yaitu memasukan emping melinjo ke dalam plastik sedangkan pengepakan menggunakan kardus besar. Sebagian kecil pengrajin $(5 \%)$ melakukan penyimpanan dalam waktu 4 
TABEL 2. AKTIVITAS PELAKU SUPPLY CHAIN EMPING MELINJO DI BAGIAN HILIR

\begin{tabular}{|c|c|c|c|c|c|c|c|c|c|c|}
\hline \multirow{3}{*}{$\begin{array}{c}\text { Pelaku Supply } \\
\text { Chain }\end{array}$} & \multicolumn{10}{|c|}{ Aktivitas (\%) } \\
\hline & \multicolumn{3}{|c|}{ Pertukaran } & \multicolumn{5}{|c|}{ Fisik } & \multicolumn{2}{|c|}{ Fasilitas } \\
\hline & $\begin{array}{l}\text { Pembe } \\
\text { lian }\end{array}$ & $\begin{array}{l}\text { Penjuo } \\
\text { lan }\end{array}$ & $\begin{array}{l}\text { Pengupa } \\
\text { san }\end{array}$ & $\begin{array}{l}\text { Pengema } \\
\text { san }\end{array}$ & $\begin{array}{l}\text { Pengepa } \\
\text { kan }\end{array}$ & $\begin{array}{l}\text { Penyimpa } \\
\text { nan }\end{array}$ & $\begin{array}{l}\text { Pengang } \\
\text { kutan }\end{array}$ & B.muat & Sortasi & Grading \\
\hline Pengrajin & $x$ & $\sqrt{ }$ & $x$ & $\sqrt{ }$ & 70 & 5 & 70 & 2,5 & 45 & 35 \\
\hline Pengumpul & $\sqrt{ }$ & $\sqrt{ }$ & $x$ & $X$ & $\sqrt{ }$ & $X$ & $\sqrt{ }$ & $X$ & $X$ & $X$ \\
\hline P. Kecil & $\sqrt{ }$ & $\sqrt{ }$ & $X$ & $X$ & $\sqrt{ }$ & $x$ & $\sqrt{ }$ & $X$ & $x$ & $X$ \\
\hline P. Besar & $\sqrt{ }$ & $\sqrt{ }$ & $x$ & $x$ & $\sqrt{ }$ & 20 & $\sqrt{ }$ & $\sqrt{ }$ & 40 & 40 \\
\hline Pengecer & $\sqrt{ }$ & $\sqrt{ }$ & $x$ & $\sqrt{ }$ & $X$ & 21,1 & $X$ & $X$ & 15,8 & 15,8 \\
\hline
\end{tabular}

Keterangan:

$\mathrm{X}$ : Semua pelaku tidak melakukan aktivitas

: Semua pelaku melakukan aktivitas

sampai 5 bulan. Pada umumnya pengrajin tidak melakukan pengangkutan karena emping melinjo diambil langsung oleh pedagang pengumpul, pedagang kecil atau pedagang pengecer.

Sortasi dilakukan pengrajin dengan cara memisahkan antara emping melinjo yang bulat sempurna dengan yang rusak dan sebanyak $45 \%$ pengrajin melakukan sortasi sedangkan grading hanya dilakukan oleh 35\% pengrajin yaitu membagi emping melinjo dalam tiga grade, pertama emping super dengan ciri-ciri tipis, bening dan berasal dari $1-2$ biji melinjo. Kedua emping dengan ciri-ciri agak tebal, warna kuning keemasan, dan berasal dari 3-4 biji melinjo, ketiga emping besar dengan ciri-ciri tebal, berasal dari 25-30 biji melinjo.

\section{Pedagang Pengumpul Emping Melinjo}

Aktivitas pertukaran yang dilakukan oleh pedagang pengumpul yaitu membeli emping melinjo dari pengrajin kemudian menjual lagi ke pedagang besar. Aktivitas fisik yang dilakukan pedagang pengumpul yaitu pengepakan, pengangkutan dan bongkar muat emping melinjo. Emping melinjo yang sudah terkumpul dari beberapa pengrajin kemudian dimasukan ke dalam karung dan dikirim ke pedagang besar menggunakan sepeda motor. Aktivitas yang dilakukan oleh pedagang pengumpul yang terakhir adalah bongkar muat.

\section{Pedagang Kecil Emping Melinjo}

Aktivitas pertukaran yang dilakukan pedagang kecil yaitu membeli emping melinjo dari pengrajin dan menjual kembali ke pedagang pengecer di Pasar Bantul. Aktivitas Fisik yang dilakukan pedagang kecil yaitu pengepakan dan pengangkutan. Pedagang kecil membawa dalam jumlah yang relatif sedikit sehingga tidak memerlukan biaya bongkar muat.

\section{Pedagang Besar Emping Melinjo}

Pedagang besar membeli emping melinjo dari pengrajin dan pedagang kecil kemudian menjual kembali ke pedagang pengecer di berbagai pasar. Aktivitas fisik yang dilakukan oleh pedagang besar meliputi pengepakan, penyimpanan, pengangkutan, dan bongkar muat. Pengepakan yang dilakukan adalah memasukan emping melinjo yang sudah dikemas ke dalam karung agar mudah dalam pengangkutan. Semua pedagang besar melakukan pengepakan, pengangkutan dan bongkar muat emping melinjo. Biasanya pedagang besar menggunakan jasa buruh gendong untuk bongakar muat emping melinjo dari tempat parkir sampai di tempat pedagang pengecer. Sebanyak $40 \%$ pedagang besar melakukan aktivitas sortasi dan grading.

\section{Pedagang Pengecer Emping Melinjo}

Aktivitas pertukaran yang dilakukan pedagang pengecer yaitu membeli emping melinjo dari pengrajin, pedagang kecil dan pedagang besar kemudian menjual langsung ke konsumen. Aktivitas Fisik yang dilakukan pedagang pengecer adalah penyimpanan dan pengemasan. Penyimpanan yang dilakukan bertujuan untuk persediaan menjelang lebaran dan hari besar lainnya agar memperoleh keuntungan yang lebih tinggi. Pengemasan dilakukan oleh semua pedagang pengecer yaitu dengan cara membungkus emping melinjo sesuai dengan pembelian konsumen.

\section{Konsumen}

Konsumen yang dimaksud dalam penelitian ini adalah seseorang yang langsung memanfaatkan atau mengkonsumsi emping melinjo dan tidak menjual kembali. Konsumen membeli emping melinjo melalui pedagang pengecer di berbagai daerah. 


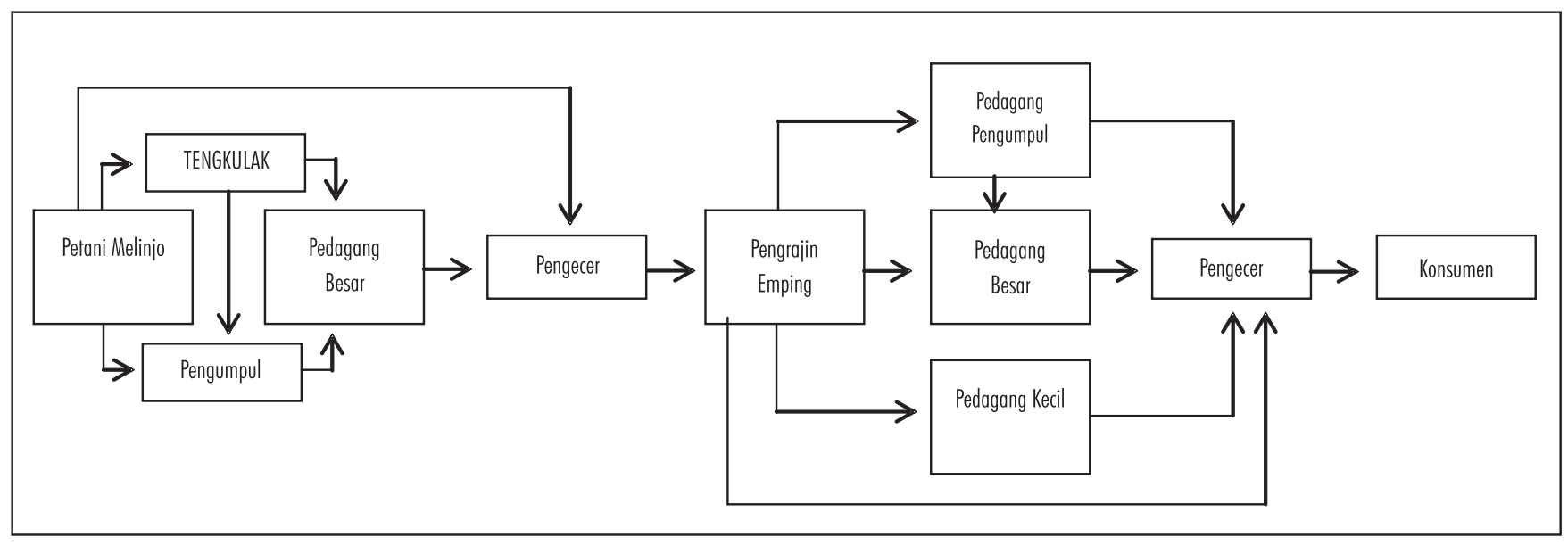

GAMBAR I. JARINGAN SUPPLY CHAIN EMPING MELINJO DI KABUPATEN BANTUL

\section{JARINGAN SUPPLY CHAIN EMPING MELINJO}

Jaringan supply chain emping melinjo dimulai dari petani melinjo di Kabupaten Bantul, Gunungkidul dan Kebumen yang menjual melinjo kepada pedagang dan pedagang melinjo menjualnya ke pengrajin emping melinjo. Melalui pedagang perantara, emping melinjo akan sampai ke tangan konsumen.

Jaringan supply chain emping melinjo di Kabupaten Bantul ada 37 jaringan yang terdiri dari 22 jaringan diawali dari petani melinjo di Gunungkidul, sebanyak 6 jaringan dimulai dari petani melinjo di Kebumen dan 9 jaringan berasal dari petani melinjo di Bantul. Supply chain emping melinjo di Kabupaten Bantul termasuk multi saluran, seperti halnya pada rantai pasokan stroberi di Kabupaten Bandung (Furqon,2014). Secara rinci jaringan supply chain emping melinjo di Kabupaten Bantul adalah sebagai berikut:

1. Petani G. Kidul - Pedagang Pengumpul G. Kidul Pedagang Besar G. kidul - Pedagang Besar Wonosari Pengrajin Emping Melinjo - Pedagang Pengecer Kotagede

- Konsumen

2. Petani G. Kidul - Pedagang Pengumpul G. Kidul Pedagang Besar G. kidul - Pedagang Besar Wonosari Pengrajin Emping Melinjo - Pedagang Pengecer Ngablak - Konsumen

3. Petani G. Kidul - Pedagang Pengumpul G. Kidul Pedagang Besar G. kidul - Pedagang Besar Wonosari Pengrajin Emping Melinjo - Pedagang Pengecer Prambanan - Konsumen

4. Petani G. Kidul - Pedagang Pengumpul G. Kidul Pedagang Besar G. kidul - Pedagang Besar Wonosari -
Pengrajin Emping Melinjo - Pedagang Pengecer Piyungan

- Konsumen

5. Petani G. Kidul - Pedagang Pengumpul G. Kidul Pedagang Besar G. kidul - Pedagang Besar Wonosari Pengrajin Emping Melinjo - Pedagang Pengecer Ngipek - Konsumen

6. Petani G. Kidul - Pedagang Pengumpul G. Kidul Pedagang Besar G. kidul - Pedagang Besar Wonosari Pengrajin Emping Melinjo - Pedagang Pengecer Demangan - Konsumen

7. Petani G. Kidul - Pedagang Pengumpul G. Kidul Pedagang Besar G. kidul - Pedagang Besar Wonosari Pengrajin Emping Melinjo - Pedagang Pengecer Imogiri

- Konsumen

8. Petani G. Kidul - Pedagang Pengumpul G. Kidul Pedagang Besar G. kidul - Pedagang Besar Wonosari Pengrajin Emping Melinjo - Pedagang Pengecer Beringharjo - Konsumen

9. Petani G. Kidul - Pedagang Pengumpul G. Kidul Pedagang Besar G. kidul - Pedagang Besar Wonosari Pengrajin Emping Melinjo - Pedagang Pengumpul A Pedagang Pengecer Beringharjo - Konsumen

10. Petani G. Kidul - Pedagang Pengumpul G. Kidul Pedagang Besar G. kidul - Pedagang Besar Wonosari Pengrajin Emping Melinjo - Pedagang Pengumpul A Pedagang Pengecer Demangan - Konsumen

11. Petani G. Kidul - Pedagang Pengumpul G. Kidul Pedagang Besar G. kidul - Pedagang Besar Wonosari - 
Pengrajin Emping Melinjo - Pedagang Pengumpul B Pedagang Pengecer Sentul - Konsumen

12. Petani G. Kidul - Pedagang Pengumpul G. Kidul Pedagang Besar G. kidul - Pedagang Besar Wonosari Pengrajin Emping Melinjo - Pedagang Besar A - Pedagang Pengecer Parakan - Konsumen

13. Petani G. Kidul - Pedagang Pengumpul G. Kidul Pedagang Besar G. kidul - Pedagang Besar Wonosari Pengrajin Emping Melinjo - Pedagang Besar B - Pedagang Pengecer Beringharjo - Konsumen

14. Petani G. Kidul - Pedagang Pengumpul G. Kidul Pedagang Besar G. kidul - Pedagang Besar Wonosari Pengrajin Emping Melinjo - Pedagang Pengumpul C Pedagang Besar C - Pedagang Pengecer Klaten Konsumen

15. Petani G. Kidul - Pedagang Pengumpul G. Kidul Pedagang Besar G. kidul - Pedagang Besar Wonosari Pengrajin Emping Melinjo - pedagang pengumpul C Pedagang Pengecer Klaten - Konsumen

16. Petani Kebumen - Tengkulak Kebumen - Pengumpul Kebumen - Pedagang Besar Kebumen- P. Besar Sayegan (Luar Daerah) - Pengecer Pajangan - Pengrajin Emping Melinjo- Pengecer Pasar Magelang - Konsumen

17. Petani Kebumen - Tengkulak Kebumen - Pengumpul Kebumen - Pedagang Besar Kebumen- P. Besar Sayegan (Luar Daerah) - Pengecer Pajangan - Pengrajin Emping Melinjo - Pengecer Pasar Borobudur - Konsumen

18. Petani Kebumen - Tengkulak Kebumen - Pengumpul Kebumen - Pedagang Besar Kebumen- P. Besar Sayegan (Luar Daerah) - Pengecer Pajangan - Pengrajin Emping Melinjo - Pengecer Pasar Muntilan - Konsumen

19. Petani G. Kidul - Pengumpul G.Kidul - Pedagang Besar G Kidul - Pedagang Besar Wonosari (Luar Daerah) Pengecer Pajangan - Pengrajin Emping Melinjo Pedagang Besar C - Pengecer Pasar Magelang - Konsumen 20.Petani G. Kidul - Pengumpul G.Kidul - Pedagang Besar G Kidul - Pedagang Besar Wonosari (Luar Daerah) Pengecer Pajangan - Pengrajin Emping Melinjo Pedagang Besar C - Pengecer Pasar Temanggung Konsumen

21. Petani G. Kidul - Pengumpul G.Kidul - Pedagang Besar G Kidul - Pedagang Besar Wonosari (Luar Daerah) Pengecer Pajangan - Pengrajin Emping Melinjo -
Pedagang Besar B - Pengecer Pasar Magelang - Konsumen 22. Petani G. Kidul - Pengumpul G.Kidul - Pedagang Besar G Kidul - Pedagang Besar Wonosari (Luar Daerah) Pengecer Pajangan - Pengrajin Emping Melinjo Pedagang Besar B - Pengecer Pasar Klaten - Konsumen 23. Petani Bantul - Pedagang Pengecer Bantul - Pengrajin Emping Melinjo- Pedagang Besar A - Pengecer Pasar Magelang - Konsumen

24. Petani Bantul - Pedagang Pengecer Bantul - Pengrajin Emping Melinjo - Pedagang Besar A - Pengecer Pasar Borobudur - Konsumen

25. Petani Kebumen - Tengkulak Kebumen - Pengumpul Kebumen - Pedagang Besar Kebumen- P. Besar Sayegan (Luar Daerah) - Pengecer Pajangan - Pengrajin Emping Melinjo - Pedagang Besar D - Pengecer Bringharjo Konsumen

26. Petani Bantul - Pedagang Pengecer Bantul - Pengrajin Emping Melinjo - Pedagang Besar E - Pengecer Pasar Bringharjo - Konsumen

27. Petani Bantul - Pedagang Pengecer Bantul - Pengrajin Emping Melinjo - Pedagang Pengumpul D - Pedagang besar B - Pengecer Pasar Magelang - Konsumen

28. Petani Bantul - Pedagang Pengecer Bantul - Pengrajin Emping Melinjo - Pedagang Pengumpul D - Pedagang besar B - Pengecer Pasar Klaten - Konsumen

29. Petani Bantul - Pedagang Pengecer Bantul - Pengrajin Emping Melinjo - Pedagang Pengumpul D - Pedagang besar C - Pengecer Pasar Magelang - Konsumen

30. Petani Bantul - Pedagang Pengecer Bantul - Pengrajin Emping Melinjo - Pedagang Pengumpul - Pedagang besar $\mathrm{C}$ - Pengecer Pasar Temanggung - Konsumen

31. Petani Kebumen - Tengkulak Kebumen - Pengepul Kebumen - Pedagang Besar Kebumen- P. Besar Sayegan (Luar Daerah) - Pengecer Pajangan - Pengrajin Emping Melinjo - Pengecer Pasar Godean - Konsumen

32. Petani Kebumen - Tengkulak Kebumen - Pengumpul Kebumen - Pedagang Besar Kebumen- P. Besar Sayegan (Luar Daerah) - Pengecer Pajangan - Pengrajin Emping Melinjo - Pengecer A - Konsumen

33. Petani Bantul - Pedagang Pengecer Bantul - Pengrajin Emping Melinjo - Pengecer B - Konsumen 34. Petani G. Kidul - Pengumpul G.Kidul - Pedagang Besar G Kidul - Pedagang Besar Wonosari (Luar Daerah) - 
Pengecer Pajangan - Pengrajin Emping Melinjo - Pengecer Pasar Bantul - Konsumen

35. Petani Bantul - Pedagang Pengecer Bantul - Pengrajin Emping Melinjo - Pedagang Kecil - Pengecer Pasar Bantul

- Konsumen

36. Petani G. Kidul - Pengumpul G.Kidul - Pedagang Besar G Kidul - Pedagang Besar Wonosari (Luar Daerah) Pengecer Pajangan - Pengrajin Emping Melinjo - Pengecer Pasar Gamping - Konsumen

37. Petani G. Kidul - Pengumpul G.Kidul - Pedagang Besar G Kidul - Pedagang Besar Wonosari (Luar Daerah) Pengecer Pajangan - Pengrajin Emping Melinjo - Pengecer Pasar Temanggung - Konsumen

\section{ALIRAN PRODUK, ALIRAN UANG, DAN ALIRAN INFORMASI SUPPLY CHAIN EMPING MELINJO \\ Aliran Produk}

Dalam suatu supply chain ada tiga macam aliran yang harus dikelola yaaitu aliran barang, aliran uang dan aliran informasi (Siagian, 2005). Pada supply chain emping melinjo, aliran produk adalah aliran barang berupa melinjo dari petani sampai pengrajin kemudian diolah akan menghasilkan emping melinjo. Emping melinjo sampai di tangan konsumen melalui pedagang pengumpul, pedagang besar, pedagang kecil dan pedagang pengecer. Dalam transaksi jual beli antara petani dan pedagang melinjo, kualitas, kuantitas dan tempat pengiriman sudah sesuai dengan kesepakatan. Akan tetapi dalam pengiriman produk $40 \%$ petani masih belum tepat waktu. Dilihat dari aspek jumlah melinjo yang diminta pengrajin, lebih dari $60 \%$ pedagang melinjo belum memenuhi kebutuhan melinjo pengrajin. Semua pedagang melinjo sudah memenuhi kualitas yang diinginkan pengrajin, sedangkan dari aspek waktu sebagian pedagang melinjo mengirim sudah tepat waktu dan lebih dari 50\% pedagang melinjo sudah mengirim barang sesuai tempat yang disepakati.

Jenis emping melinjo yang diproduksi oleh pengrajin di Kabupaten Bantul adalah original dengan kualitas super dan biasa. Diihat dari aspek jumlah emping melinjo yang dipasok oleh pengrajin sudah sesuai dengan yang diminta. Berdasarkan aspek kualitas emping melinjo yang dihasilkan oleh pengrajin sudah sesuai dengan pedagang emping melinjo. Sebanyak $60 \%$ pengrajin sudah mengirim tepat waktu dan sebanyak $57,5 \%$ mengirim sesuai dengan tempat yang disepakati.

Aliran produk emping melinjo dari pedagang pengumpul ke pedagang besar berjalan lancar karena produk emping melinjo yang dijual pedagang pengumpul sesuai kesepakatan dilihat dari aspek kuantitas, kualitas, waktu dan tempat pengiriman. Dilihat dari jumlah dan kualitas emping melinjo yang dipasok oleh pedagang kecil dan pedagang besar sudah sesuai dengan permintaan. Konsumen yang membeli emping melinjo di pedagang pengecer dapat memilih sendiri sesuai dengan jenis dan kualitas yang diinginkannya. Aliran produk/ barang pada supply chain emping melinjo yang lancar, terjadi juga pada rantai pasok gula siwalan di Kabupaten Sumenep yang sudah baik, Sustiyana et al (2013). Keadaan ini berbeda dengan supply chain daging sapi di Kabupaten Jember yang menunjukkan bahwa aliran produk belum optimal (Emhar et. al., 2014).

\section{Aliran Uang}

Aliran uang dalam supply chain emping melinjo bergerak dari konsumen ke petani melinjo. Konsumen dalam penelitian ini adalah orang yang membeli emping melinjo di pedagang pengecer. Aliran uang dari konsumen ke pedagang pengecer ke pengrajin berjalan lancar demikian juga aliran uang dari pedagang pengecer ke pedagang kecil serta ke pedagang pengumpul karena sistem pembayarannya secara langsung dan cash demikian juga dengan aliran uang dari pengrajin emping melinjo ke pedagang melinjo dan dari pedagang melinjo ke petani. Keadaan ini berbeda dengan yang terjadi pada supply chain daging sapi di Kabupaten Jember, bahwa aliran keuangan tidak berjalan secara optimal (Emhar et. al., 2014).

\section{Aliran Informasi}

Aliran informasi yang terjadi dalam supply chain emping melinjo bergerak dua arah, yaitu aliran yang bergerak dari petani melinjo ke pengrajin kemudian sampai ke konsumen serta aliran yang bergerak sebaliknya dari konsumen ke pengrajin kemudian sampai di petani melinjo. Alat yang biasa digunakan oleh pelaku supply chain untuk berkomunikasi yaitu handphone.

Aliran informasi dari petani ke pedagang melinjo kurang lancar, hal ini terjadi pada petani yang menjual melinjo dengan sistem tebasan. Aliran informasi dari pedagang melinjo ke pengrajin berjalan lancar dan sebagian besar pedagang melinjo sudah mengetahui kualitas yang dibutuhkan pengrajin. Akan tetapi informasi yang berkaitan dengan kuantitas yang diminta dan waktu pengiriman sudah sesuai.

Informasi tempat pengiriman dan kualitas emping dari 
pedagang ke pengrajin sudah lancar karena masing-masing pengrajin sudah mempunyai pasarnya sendiri. Pedagang meminta emping melinjo jenis original dengan kualitas super dan biasa. Informasi yang kurang lancar terjadi pada jumlah yang diminta pedagang yang melebihi jumlah yang diproduksi.

Aliran informasi tentang kualitas emping melinjo, tempat pengiriman, dan jenis emping melinjo yang diminta dari pedagang pengumpul, pedagang kecil, dan pedagang besar ke pengecer pada umumnya lancar. Aliran informasi yang kurang lancar terjadi pada waktu pengiriman dan kuantitas. Hal ini karena tidak ada stok atau produksi belum selesai dan permintaan pedagang pengecer banyak padahal emping melinjo tidak hanya dijual ke satu pedagang pengecer. Aliran informasi tentang jenis dan kualitas emping melinjo yang diminta konsumen lancar karena konsumen dapat memilih emping melinjo sesuai dengan jenis dan kualitas yang diinginkannya. Aliran informasi pada supply chain emping melinjo di Kabupaten Bantul dapat disimpulkan masih belum lancar. Keadaan ini berbeda dengan yang terjadi pada rantai pasok gula siwalan di Kabupaten Sumenep yang sudah baik, Sustiyana et. al. (2013)

\section{EFISIENSI SUPPLY CHAIN EMPING MELINJO}

Efisiensi supply chain dianalisis menggunakan Program Linier (linear programming) dengan tujuan meminimumkan biaya supply chain dengan kendalanya pasokan emping melinjo dari pengrajin dan permintaan emping melinjo di berbagai pasar di Bantul, Kota Yogyakarta, Sleman, Klaten, Magelang dan Temanggung, dimana konsumen membeli emping melinjo yang berasal dari Kabupaten Bantul. Hasil analisis disajikan pada tabel 3 .

Berdasarkan tabel 3 diketahui bahwa ke 22 jaringan supply chain yang efisien terdiri dari 14 jaringan diawali dari petani melinjo di Gunungkidul, 5 jaringan dari petani di Kebumen dan 3 jaringan diawali dari petani melinjo di Bantul. Hal ini menunjukkan bahwa sebagian besar pengrajin emping melinjo di Kabupaten Bantul menggunakan melinjo yang berasal dari Gunungkidul. Dengan kata lain melinjo dari Gunungkidul mempunyai daya saing yang lebih kuat dibandingkan daerah Kebumen dan Bantul.

Hasil analisis menunjukkan bahwa semua permintaan konsumen akan emping melinjo sudah terpenuhi dari pengrajin emping melinjo di Bantul. Produksi emping melinjo di Bantul mencapai $25.361 \mathrm{~kg} /$ minggu dan telah didistribusikan ke konsumen melalui pedagang pengecer di berbagai pasar di Bantul, Sleman, Kota Yogyakarta, Klaten,
TABEL 3. DISTRIBUSI DAN PEMENUHAN PERMINTAAN EMPING MELINJO PADA KEADAAN BIAYA MINIMUM

\begin{tabular}{llllll}
\hline No. & Produksi/ Tujuan & $\begin{array}{l}\text { Produksi/ } \\
\text { Permintaan } \\
(\mathrm{kg})\end{array}$ & $\begin{array}{l}\text { Terdistribusi/ } \\
\text { Terpenuhi } \\
(\mathrm{kg})\end{array}$ & $\begin{array}{l}\text { Sisa/ } \\
\text { Kekurangan } \\
(\mathrm{kg})\end{array}$ & $\begin{array}{l}\text { Dual } \\
\text { Price } \\
(\mathrm{Rp})\end{array}$ \\
\hline 1 & Pengrajin & 25361 & 25361 & 0 & 2728 \\
2 & PasarKotagede & 420 & 420 & 0 & 2112 \\
3 & Pasar Ngablak & 210 & 210 & 0 & 2198 \\
4 & Prambanan & 350 & 350 & 0 & 2148 \\
5 & Piyungan & 567 & 567 & 0 & 2118 \\
6 & Pasar Ngipek & 105 & 105 & 0 & 2348 \\
7 & Pasar Demangan & 105 & 105 & 0 & 1948 \\
8 & Pasar Imogiri & 700 & 700 & 0 & 2045 \\
9 & Pasar Bringhario & 1680 & 1680 & 0 & 2102.7 \\
10 & Pasar Parakan & 1400 & 1400 & 0 & 252.3 \\
11 & Pasar Klaten & 5600 & 5600 & 0 & 0 \\
12 & Pasar Sentul & 700 & 700 & 0 & 793 \\
13 & Magelang & 1190 & 1190 & 0 & 2148 \\
14 & Borobudur & 700 & 700 & 0 & 2148 \\
15 & Muntilan & 2100 & 2100 & 0 & 2048 \\
16 & Klaten & 5600 & 5600 & 0 & 1584 \\
17 & Bringhario & 1680 & 1680 & 0 & 2038 \\
18 & Godean & 546 & 546 & 0 & 2198 \\
19 & Bantul & 245 & 245 & 0 & 2148 \\
20 & Gamping & 245 & 245 & 0 & 2198 \\
21 & Temanggung & 1050 & 1050 & 0 & 2148 \\
22 & Pengecer A & 49 & 49 & 0 & 2248 \\
23 & Pengecer B & 119 & 119 & 0 & 2568 \\
\hline & & & & & \\
\hline
\end{tabular}

Temanggung dan Magelang sesuai permintaannya.

Pengrajian emping di Kabupaten Bantul yang menggunakan melinjo dari Gunungkidul dapat meminimumkan biaya supply chain jika mendistribusikan empingnya menggunakan 14 jaringan sampai ke pengecer di pasar Kotagede (420 kg), Ngablak (210 kg), Prambanan (350 kg), Piyungan (567 kg), Ngipek (105 kg), Demangan (105 kg), Imogiri (700 $\mathrm{kg}$ ), pasar Beringharjo (1680 kg), pasar Sentul $700 \mathrm{~kg}$ ), pengecer di Parakan $(1400 \mathrm{~kg})$, Klaten $(5600 \mathrm{~kg})$, pasar Bantul (245 kg), pasar Gamping (245) dan Temanggung (1050 kg). Sedangkan pengrajin emping yang menggunakan melinjo dari 
Kebumen mengeluarkan biaya minimum jika pengrajin mendistribusikan empingnya menggunakan 5 jarinagn sampai ke pasar Magelang (1190 kg), pasar Borobudor (700 $\mathrm{kg}$ ), pasar Muntilan (2100 kg), pasar Godean (546 kg) dan pengecer A di Bantul (49 kg). Pengrajin yang bahan bakunya berasal dari petani di Bantul, mengeluarkan biaya supply chain minimum jika distribusi emping melinjo menggunakan 3 jaringan sampai ke Pengecer B di Bantul (119 kg), pasar Beringharjo $(1680 \mathrm{~kg})$ dan pasar Klaten $(5600 \mathrm{~kg})$. Supply chain emping melinjo dengan alokasi tersebut membutuhkan biaya yang minimum yaitu sebesar Rp. 33.969.264,00/ minggu. Biaya ini meliputi biaya pengupasan, pengemasan, penyimpanan, transportasi, bongkar muat, sortasi dan grading.

\section{KESIMPULAN}

Pelaku supply chain emping melinjo terdiri dari pelaku di bagian hulu meliputi petani dan pedagang melinjo serta pelaku di bagian hilir yaitu pengrajin dan pedagang emping melinjo. Baik pelaku di bagian hulu maupun hilir melakukan aktivitas pertukaran (pembelian dan penjualan), fisik (pengupasan, pengemasan, penyimpanan, pengangkutan dan bongkat muat) serta aktivitas fasilitas (sortasi dan grading).

Terdapat 37 jaringan supply chain emping melinjo mulai dari hulu hingga hilir, yaitu diawali dari petani melinjo yang berada di wilayah DIY (Bantul, Gunungkidul) dan Kebumen (Jawa Tengah) melewati pedagang melinjo, pengrajin emping, pedagang emping hingga konsumen emping yang tersebar di wilayah Bantul, Sleman, Gunungkidul, Kota Yogyakarta, Klaten, Solo, Magelang dan Temanggung.

Berdasarkan analisis linear programming, biaya distribusi akan minimum jika 22 jaringan digunakan, yaitu 14 jaringan diawali dari petani melinjo di Gunungkidul, 5 jaringan dari petani melinjo di Kebumen dan 3 jaringan dari petani melinjo di Bantul, dan berakhir pada konsumen di berbagai daerah di DIY serta Jawa Tengah.

Semua jaringan supply chain memungkinkan digunakan dan Supply Chain tetap akan efisien jika produksi emping di Kabupaten Bantul meningkat. Oleh karena itu diperlukan pengelolaan usahatani melinjo yang lebih baik agar produksi melinjo meningkat sehingga produksi emping melinjo juga akan naik.

\section{DAFTAR PUSTAKA}

Badan Pusat Statistik (BPS). 2013. Bantul dalam Angka. Yogyakarta

Chopra, S., \& Meindl, P. 2001. Supply Chain Management-Strategy, Planning and Operating. Pretice Hall Inc, New Jersey.

Dinas Perindustrian, Perdagangan dan Koperasi. 2012. Data Industri
Makanan di Kabupaten Bantul.

Emhar, A., Joni, M. M. A., \& Titin A. 2014. Analisis rantai pasok (supply chain) daging sapi di Kabupaten Jember. Berkala IImiah Pertanian 1(3): 53-61.

Furqon, C. 2014. Analisis manajemen dan kinerja rantai pasokan stroberi di Kabupaten Bandung. Image III(2): 109-126.

Indrajit, R. E., \& Richardus, D. 2002. Konsep Manajemen Supply Chain. PT. Gramedia Widiasarana Indonesia, Jakarta.

Kotler, P. 2003. Marketing Management. Eleventh Edition. Prentice Hall Inc, New Jersey.

McCullen, P. \& Towill, D. 2002. Diagnosis and reduction of bulwhip effect in supply chain. Supply Chain Management: At International Journal 7(3): 164-179.

Moharana, H. S. et. al. 2010. Coordination, collaboration and integration for supply chain management. International Journal of Interscience Management Review (IMR) 2(2): 46-50.

Pujawan, I. Y. 2005. Supply Chain Management. Guna Widya, Surabaya. Sarmah, S. P., Acharya, D., \& Gayol, S. K. 2005. Buyer vendor coordination models in supply chain management. European Journal of Operational Research 105: 1- 15.

Siagian,Y. M. 2005. Supply Chain Management. Grasindo, Jakarta.

Sustiyana, Syafrial, \& Mangku, P. 2013. Analisis supply chain dan efisiensi pemasaran gula siwalan di Kabupaten Sumenep Jawa Timur. Jurnal Habitat XXIV(2): 110-119.

Widodo, K. H., Abdullah, A., \& Kharies, P. D. A. 2010. Sistem supply chain crude palm oil Indonesia dengan mempertimbangkan aspek economical revenue, social welfare dan environment. Jurnal Ternik Industri 12(1): $47-53$. 